Kansas State University Libraries

New Prairie Press

\title{
Transformative Learning Intervention: Effect on Functional Health Literacy and Diabetes Knowledge in Older African Americans
}

Daphne W. Ntiri

Wayne State University

Merry Stewart

University of Detroit Mercy

Follow this and additional works at: https://newprairiepress.org/aerc

Part of the Adult and Continuing Education Administration Commons

(c) (1) (9)

This work is licensed under a Creative Commons Attribution-Noncommercial 4.0 License

\section{Recommended Citation}

Ntiri, Daphne W. and Stewart, Merry (2010). "Transformative Learning Intervention: Effect on Functional Health Literacy and Diabetes Knowledge in Older African Americans," Adult Education Research Conference. https://newprairiepress.org/aerc/2010/papers/61

This is brought to you for free and open access by the Conferences at New Prairie Press. It has been accepted for inclusion in Adult Education Research Conference by an authorized administrator of New Prairie Press. For more information, please contact cads@k-state.edu. 


\title{
Transformative Learning Intervention: Effect on Functional Health Literacy and Diabetes Knowledge in Older African Americans
}

\author{
Daphne W. Ntiri, Wayne State University, USA \\ Merry Stewart, University of Detroit Mercy, USA
}

\begin{abstract}
This study evaluated the effect of a transformative learning intervention on functional health literacy and diabetes knowledge in older African Americans. Twenty participants from senior community centers completed a six session intervention and three health literacy tests. Participants' verbal responses affirmed the positive influence of the TL principles.
\end{abstract}

\section{Transformative Learning}

Research pertaining to adult learning theories has been centered in traditional educational environments (e.g. classrooms). However, adult learning theories are reaching beyond traditional contexts. These extended contexts include health care environments. The exploration of educational pedagogies for adults in health care has been driven by longer life spans and the increasing incidence of chronic illnesses (Chronic Illness - The Rise of Chronic Illness, 2007).

Educators have explored the process of change in adults over the years. Adult educators have been shifting from a complete reliance on traditional pedagogical approaches to alternative learning approaches (Knowles, 1984). Knowles stated that the goal of these alternative approaches should be to motivate adults to become more active in the learning process. Active learning affords adults the opportunities to develop new frames of reference and see the world differently from where they were before. Green (1981) advocated that active learning principles emphasize learner choice more than expert control.

Mezirow (1996) has expanded the theoretical debate further with his focus on transformative learning (TL). Mezirow declared that TL is a social process by which one can construct and apply new meaning to one's experience as a guide to action. In other words, TL is viewed as an effective method to expand one's consciousness and bring about the required social change as is advocated in this study. Additionally, TL is a self-directed process whereby learners use their initiatives with or without the help of others to determine the information they need and seek ways to acquire it (Cranton, 2006).

\section{Literature Review}

\section{Transformative Learning and Self-Management}

Tennant (2000) theorized that TL is an effective instrument for self-development and change because it: a) offers new possibilities for understanding learning and its relation to selfdevelopment and change and b) can improve self- esteem and help to discover the "authentic" self. On the journey to being transformed, learners need to build trust, determine their needs and expectations and create learning experiences that may change their current frame of reference. Tennant states that this process will help learners to gain access to information that will help them orient themselves to a world that may be different from what it was before.

The power of TL is widely acknowledged for its change agent qualities. This theory is particularly applicable to the health care environment where empowering the patient to 
understand the significance of self-management is important to an individual's well-being. Patients currently have greater personal responsibility and treatment decisions for various health problems. Health care professionals equally have a major role in promoting techniques for effective self-management (Rager, 2003).

\section{Health Literacy and Older African Americans Living with Diabetes}

Education is critical for persons living with diabetes since the majority of day-to-day decisions about diabetes management are made by the individual (Funnell, 2006; Skovlund, 2004). The emphasis on education to aid in appropriate self-management is viewed as even more important for older African Americans, who not only have a higher incidence of diabetes, but also of related complications (American Diabetic Association [ADA]), 2008; Baker et al., 2002; Sudore et al., 2006). Self-management is crucial to maintaining target glycemic levels and preventing complications in these individuals. A primary barrier to diabetes education in the older-aged population has been reported to be inadequate functional health literacy or the ability to read and understand prescription and nutrition labels and other basic health related print materials ( Baker, Gazmararian, Sudano, \& Patterson, 2000; Baker et al., 2002; Edmunds, 2005; Kim, Love, Quistberg, \& Shea, 2005; Morrow et al., 2006; Robbins, 2008; Rothman et al., 2004; Schillinger et al., 2002; Schillinger, Barton, Karter, Wang \& Adler, 2006; Sudore et al., 2006).

\section{Method}

\section{Setting and Recruitment}

Twenty participants were recruited from two urban community senior centers in Detroit, Michigan. Eligible participants were 55 years or older and diagnosed with diabetes. Cognitive impairment and low visual acuity are suggested to affect reading comprehension and therefore included as exclusion criteria (Baker, Gazmararian, Sudano, \& Patterson, 2000). Fifty-one African American seniors who were being treated for diabetes were initially identified as prospective participants from both centers. They were informed of monetary compensation upon completing the study.

\section{Data Collection Instruments and Procedure}

Baseline cognitive testing (e.g. MacNeil-Lichtenberg Decision Tree [MacNeil \& Lichtenberg, 2000]) and visual acuity using the Rosenberg Handheld Vision Chart were used to determine eligible participants. A 15-item Geriatric Depression Scale (GDS) was also completed by all participants to evaluate for depression as a possible indicator of diminished cognitive function (Sheikh \& Yesavage, 1986). Diabetes knowledge was measured by an adaptive version of the 23 - item multiple choices Diabetes Knowledge Test (DKT). Health literacy was evaluated by two measures - the short-form of the Test of Functional Health Literacy (sTOFHLA) and the Literacy for Diabetes (LAD).

\section{Transformative Learning Intervention}

The TL intervention focused on interactive communication related to common diabetes terminology and was divided into six sessions. The objectives and content of the intervention were developed and facilitated by an African American advanced practice nurse educator. Scheduling of the TL intervention was selected by the participants. Sessions were scheduled one 
hour twice a week over three consecutive weeks. Each session was conducted during the same time and days of the week. Each session was designed to foster curiosity and reflection on both old and new information related to self-management of diabetes mellitus. Primary topics for each session were: 1) what is diabetes, 2) eating; 3) exercising; 4) medications; 5) common effects of diabetes, and 6) self-management of diabetes. The description and objectives for the intervention were reviewed and approved by a panel of diabetic educators/advance practice nurses.

\section{Transformative Learning Intervention/Classroom Activity}

Activity related to the TL intervention included placing large print posters of common diabetes words, phrases and definitions on the classroom walls related to the focused topic of each session. New posters were added alongside previous posters during each of the six sessions. Information from "The Diabetic Channel Series", -- a set of large font and low literacy level pamphlets (American Diabetic Association, 2001) was distributed along with other ADA materials. The information from higher literacy level pamphlets was rephrased to a $4^{\text {th }}$ to $6^{\text {th }}$ grade literacy level. Examples of information included signs and symptoms of diabetes, target blood sugar levels in fasting state and post meal states; and desired hemoglobin AIC level (a standard test to determine the average blood glucose control over a 3 month period for persons with diabetes). All participant information was maintained in personal folders in which participants were directed to underline words and write notes or personal reflections. Terms associated with diabetes were carefully and repeatedly pronounced and defined, using language considered as standard among health practitioners and language more commonly used by lay participants. Additionally, personal-directed questions were used to encourage participants' lived experiences through stories, questions, responses, and additional terms related to selfmanagement of diabetes. One of the initial facilitative questions was "What is diabetes and why is it important for you to know about diabetes? Supplemented information from the nurse facilitator and the ADA materials were integrated with the participant's discussion to give new information or to clarify diabetes related information. One-to-one facilitator and individual discussions were also encouraged by the facilitator after each session.

\section{Results}

\section{Demographic Profile of Participants}

The participants' ages ranged from 57 to 84 years (Mean $=68.1$ years). Sixty five percent were female and $35 \%$ were males. The educational survey of the participants revealed that $20 \%$ had obtained less than a high school education, 35\% $(\mathrm{n}=7)$ had obtained a high school diploma, and $45 \%(n=9)$ had obtained an associate degree or stated having attended some college. The majority or $75 \%(n=15)$ of the participants indicated a diagnosis of diabetes for greater than 5 years. Fifty five percent $(n=11)$ stated participation in at least one previous diabetes class/program. Self management of diabetes was indicated by the majority of participants who reported either taking medication (90\%) and/or self check of blood sugars $(68 \%)$.

\section{Post-TL Intervention Responses from Participants}

A positive effect of the TL interventions was also indicated by the following participants' responses taken from demographic data, remarks during the intervention sessions, and conversational summary with the nurse facilitator following the final literacy and diabetes

knowledge tests. A 74 year old widowed male with known diabetes for five years reported 
coming to the center most weekday mornings since being widowed and usually only participating in recreational card games. This participant reported having less than $7^{\text {th }}$ grade education and admitted not always being comfortable in group educational activities. After the first session, this participant rescheduled his card games in order to be available for each session. This participant was also noted to listen only in the initial sessions, but by the $3^{\text {rd }}$ session, increasingly participated by sharing personal stories of his experiences with diabetes. This participant's post DKT score of $50 \%$ as compared with his baseline score of $14 \%$ also reflected greater diabetes knowledge.

Other participants also indicated greater efforts to achieve target blood sugar levels through exercise and dietary management: "I have started purposely walking more". "I joined a senior swimming program, I feel much better". "I am trying harder to watch what I eat".

\section{Discussion}

This study supports that the utilization of TL principles in health education formats may significantly motivate those living with chronic illnesses to search for knowledge and improve self-management of their illnesses. The s-TOFHLA literacy scores and diabetic test scores were significantly increased following the TL intervention utilized in this study. The insignificant difference between the immediate-post and delayed-post intervention literacy scores and DKT scores suggest that test-retest measures were not a factor in the increase of scores.

In comparison, the LAD scores which indicated ability to recognize and pronounce common health related terms did not significantly differ at baseline and post-intervention times. This difference in the LAD literacy scores from the s-TOHFLA raises questions as to the effectiveness of word recognition tests in evaluating health literacy levels or the ability to comprehend and use health information. The comparison of the LAD to the s-TOFHLA was not a focus of this study. The investigators acknowledge, however that further study with a larger sample and control group is important for determining if both tests similarly measure literacy.

Similar to other studies, age was found to correlate inversely with the s-TOHFLA scores (Baker et al., 2002). However, this finding was only indicated at the pre-intervention level. Postintervention findings support that the active involvement of older individuals in the provision of health care information may be a key to improved functional health literacy.

Higher mean DKT scores correlated significantly with a greater number of years diagnosed with diabetes, which is an expected finding. However, neither age, level of education, nor having had a previous diabetes class significantly correlate with the higher DKT scores. These findings again suggest that the application of TL interventions may be an effective method for both improving functional health literacy and promoting effective self-management for individuals of different ages and educational backgrounds who live with this chronic disease. However, the investigators acknowledge that factors such as the length of time since previous diabetes classes and the characteristics of such classes were not assessed. Experimental design studies are recommended to compare diabetic education programs that utilize TL principles with other established program formats.

The frequency of self blood sugar checks was found to be significantly associated with DKT scores only at baseline. This finding suggests that adherence to self-management procedures alone does not necessarily represent the diabetic patient's level of knowledge regarding diabetes. Again, further study is recommended in this area. 
The TL intervention in this study was conducted with active older African American seniors, most of who were identified at baseline as having adequate functional health literacy levels. Therefore, the results of the study cannot be generalized to all older urban African Americans living with diabetes. Participants in both settings were familiar with the specific senior center and mostly well known to each other secondary to involvement in other center activities. These factors may have contributed to an environment of comfort and trust, thus influencing the positive outcome of this study.

Limitations also existed relative to assessments within the domain of diabetes knowledge. Only test scores were evaluated pre and post the TL intervention. The addition of pre and post glycemic levels and self-management changes (e.g. frequency of self-checking blood sugars and diet habits) is suggested in future studies as a more compelling reflection of diabetes knowledge (Powell, Hill, \& Clancy, 2007). Comparative educational methods as well as follow-up with other interactive classes or diabetes informational activities were also not performed. An added qualitative design is suggested to evaluate the validity of this study. The self-reflections documented from participants of this study along with the statistical findings do imply, however, that interactive diabetes education that is formatted to be part of the participants' lived experience may significantly increase diabetes knowledge and improve functional health literacy.

Further research is indicated in the development of educational approaches utilizing a TL process, particularly for individuals living with diabetes who must make day-to-day decisions related to self-management of their illness. This is of major importance for older African Americans who disproportionately suffer from chronic illnesses and associated complications. Educational activities that utilize TL principles may significantly motivate those living with chronic illnesses to increase their search for knowledge and may promote improved selfmanagement.

\section{References}

American Diabetic Association. (2008). Diabetes statistics. Retrieved September 5, 2008 from http://www.diabetes.org/diabetes-statistics.jsp ADA

American Diabetic Association. (2004). The diabetic channel series. Alexandria, VA: Author.

Baker, D., Williams, M., Parker, R., Gazmararian, J., \& Nurss, J. (1999). Development of a brief test to measure functional health literacy. Patient Education Counseling, 38, 33-42. doi:10.1016/S0738-3991(98)00116-5

Baker, D., Gazmararian, J., Sudano, J., \& Patterson, M. (2000). The association between age and health literacy among elderly persons. Journals of Gerontology. Series B: Psychological Sciences and Social Sciences, 55B, S368-74.

Baker, D., Gazmararian, J., Williams, M., Scott, T., Parker, R., Green, D., Junling, R., \& Peel, J. (2002). Functional health literacy and the risk of hospital admission among medicare managed care enrollees. American Public Health Association, Inc, 92, 1278-1283.

Chronic Illnesses - The rise of chronic illness. (2007). Retrieved September 5, 2008 from http://family.jrank.org/pages/258/Chronic-Illness-Rise-Chronic-Illness.html

Cranton, P. (2006). Understanding and promoting transformative learning ( ${ }^{\text {nd }}$ ed). San Francisco: Jossey-Bass.

Edmunds, M. (2005). Health Literacy a barrier to patient education. The Nurse Practitioner. 30, 54-56. 
doi:10.1097/00006205-200503000-00008

Fitzgerald, J., Funnell, M., Hess, G. , Barr, P., Anderson, R., \& Davis, W. (1998). The reliability and validity of a brief diabetes knowledge test. Diabetes Care, 21, 706-710. doi:10.2337/diacare.21.5.706;

Freire, P. (1970). Pedagogy of the oppressed. New York: Seabury Press.

Freire, P. (1973). Education for critical consciousness. New York: Seabury Press.

Funnell, M. (2006). The diabetes attitudes, wishes, and needs (DAWN) study. Clinical Diabetes, $24,154-155$.

Green, L. W. (1981). Emerging federal perspectives on health promotion. Health Promotion Monographs, 1. New York: Teachers College Press.

Kim, S., Love, F., Quistberg, D., \& Shea, J. (2005). Association of health literacy with selfmanagement behavior in patients with diabetes. Diabetes Care, 27, 2980-2982.

Knowles, M. S. and Associates. (1984). Andragogy in action: Applying modern principles of adult learning. San Francisco: Jossey-Bass.

MacNeil, S. E. \& Lichtenberg, P. A. (2000). The MacNeill-Lichtenberg decision tree: a unique method of triaging mental health problems in older medical rehabilitation patients. Archives of Physical Medicine and Rehabilitation, 81, 618-622.

Mezirow, J. (1996). Transformation theory of adult learning. [Special issue]. OPTIONS: Journal of the Michigan Association for Adult and Continuing Education, 10 (1).

Morrow, D., Clark, D., Tu, W., Wu, J., Weiner, M., Steinley, D., \& Murray, M. (2006). Correlates of health literacy in patients with chronic heart failure. The Gerontologist, 46(5), 669-676.

Nath, C., Sylvester, S., Yasek, V., \& Gunel, E. (2001). Development and validation of a literacy assessment tool for persons with diabetes. The Diabetes Educator, 27, 857-864. doi:10.1177/014572170102700611

Pilling-Cormick, J. (1997). Transformative and self-directed learning in practice. New Direction for Adult and Continuing Education, 74, 69-77.

Rager, K. B. (2003). The self-directed learning of women with breast cancer. Adult Education Quarterly, 53, 277-293. doi:10.1177/0741713603254030

Rothman, R., DeWalt, D., Robb, M., Bryant, B., Shintani, A., Britton, C., Morris, W. \& Pignone, M. (2004). Influence of patient literacy on the effectiveness of a primary care-based diabetes disease management program. Journal American Medical Association, 292, 1711-1716. doi:10.1001/jama.292.14.1711

Schillinger, D., Barton, L., Karter, A., Wang, F., \& Adler, N. (2006). Does literacy mediate the relationship between education and health outcomes? A study of a low-income population with diabetes. Public Health Reports, 121, 245-254.

Schillinger, D. , Grumbach, K., Piette, J. , Wang, F., Osmond, J., Daher, C., Palacios, J. , Sullivan, D. , \& Bindman, B. (2002). Association of health literacy with diabetes outcomes. Journal of American Medical Association, 288, 475-482. doi:10.1001/jama.288.4.475

Sheikh J. I., \& Yesavage, J. (1986). Geriatric depression scale: Recent evidence and development of a shorter version. In T. L. Brink (Ed.), Clinical gerontology: A guide to assessment and intervention (pp. 165-173). NY: The Haworth Press.

Skovlund, S. (2004, May). Diabetes attitudes, wishes, and needs. Diabetes Voice, 4-11. 
Sudore, R., Mehta, K., Simonsick, E., Harris, T., Newman, A., Satterfield, S., Rosano, C., Rooks, R., Rubin, S., Ayonayon, H., \& Yaffe, K. (2006). Limited literacy in older people and Disparities in health and healthcare access. Journal of the American Geriatrics Society, $54,770-776$.

Tennant, M. (2000). Adult learning for self-development and change. In Wilson, A. L. and Hayes, E. R. (Eds.) Handbook of adult and continuing education (pp. 87-100). San Francisco: Jossey Bass. 